SCIENTIFIC REPORT

\title{
Bioavailability of fluorescein from a new drug delivery system in human eyes
}

\author{
A Steinfeld, A Lux, S Maier, R Süverkrüp, M Diestelhorst
}

Br J Ophthalmol 2004;88:48-53

Aim: To assess the ocular bioavailability of fluorescein from a novel drug delivery system compared with one single preservative free eye drop.

Methods: Part A: In a randomised study 10 volunteers applied the lyophilisate to one eye and a conventional fluorescein eye drop to the fellow eye. Fluorophotometry was performed before and every 2 minutes up to 30 minutes after application in the cornea and anterior chamber. Part B: Another 10 volunteers applied each form of the application. Fluorophotometry was performed before, +2 minutes, and at $+8,+10,+12$ hours. The dose corresponding to a single fluorescein dose of the lyophilisate was $68 \mathrm{I} \mu \mathrm{g}$ fluorescein SE $0.17 \%$.

Results: Part A: During the first 30 minutes after administration of the preservative free eye drop of $40 \mu \mathrm{g}$ the corneal and anterior chamber concentration means were up to 16 times higher in eyes treated with the lyophilisate. Part B: 812 hours after application the mean fluorescein concentration in the cornea of the lyophilisate group was two times higher than at baseline. Eyes treated with eye drops had baseline values at $+8,+10$ and +12 hours.

Conclusion: A significantly better bioavailability was achieved in human eyes by using lyophilisate compared with the same dose from a conventional eye drop. Lyophilisates are a favourable alternative to conventional eye drops since they have no preservatives, higher long term stability, no pH adjustment, and easy handling.

C onventional eye drops represent nearly $90 \%$ of the marketed formulations used in the treatment of acute and chronic diseases. ${ }^{12}$

Elderly patients find the application of conventional eye drops difficult, since they are unable to recline their head more than $55^{\circ}$ without feeling dizzy. ${ }^{3}$ Several eye drops may flood the eye with medication, leading to overtreatment resulting in topical and systemic side effects due to the rapid absorption of the active ingredient via the nasopharyngeal mucosa. ${ }^{45}$ The extensive precorneal fluid loss caused by the drainage and high tear fluid turnover during the application of conventional ophthalmic water solutions and suspensions with ocular tissues is short $(\sim 1$ minute $) .{ }^{6}$ This is one of the disadvantages of high concentrations being administered in conventional ocular therapy.

Another important disadvantage of conventional eye drops is the use of preservatives. Preservatives are meant to destroy micro-organisms and protect the eye against possible infections, but their action is non-specific and they have been proved to damage ocular tissues. ${ }^{78}$

An ideal form of application should meet the following criteria: easy use; neutral $\mathrm{pH}$ value and absence of preservatives; a more linear drug inflow into the eye; sterile true single dosage; minimal discomfort; minimal influence on visual acuity. ${ }^{1}$ In the past there have been numerous developments of new forms of application like the collagen shield, NODS, or Ocusert which were introduced unsuccessfully. ${ }^{9-11}$

A new preservative free, freeze dried ophthalmic drug delivery system (lyophilisate) has been developed (fig 1). In a first study the safety and tolerability of the lyophilisate (placebo) was compared with a conventional, preservative free tear film substitute eye drop. The lyophilisate demonstrated a very good tolerability and excellent safety. ${ }^{12}$ In a phase II study Dinslage et al ${ }^{1}$ documented a significantly better ocular bioavailability of fluorescein derived from the lyophilisate compared with the identical dose of fluorescein from a conventional eye drop during the first 3 hours after application. The aim of this study was to compare the ocular bioavailability of fluorescein from lyophilisate with conventional eye drops during the first 30 minutes after application and up to 12 hours after application.

\section{METHODS}

Part A

In an open label, randomised, clinical study 10 healthy volunteers (six men, four women) with a mean age of 25 years (minimum: 24, maximum: 27 years) applied a lyophilisate to one eye and a preservative free fluorescein eye drop to the fellow eye. Following randomisation volunteers applied the lyophilisate to the left eyes and the conventional eye drops to the right eyes and vice versa. The fluorescein dose of the lyophilisate was $68 \mu \mathrm{g}$ corresponding to a single, preservative free eye drop of $40 \mu \mathrm{l}$ fluorescein SE $0.17 \%$ (Alcon GmbH, Germany).

Since direct non-invasive objective measurements of antiglaucomatous medications or antibiotics in the living human anterior chamber are not available, anterior chamber fluorophotometry (Fluorotron Master II; Ocumetrics, Palo Alto, CA, USA) was used as a non-invasive, observer independent comparison of the fluorescein bioavailability received with the two drug delivery systems. ${ }^{13}{ }^{14}$ The

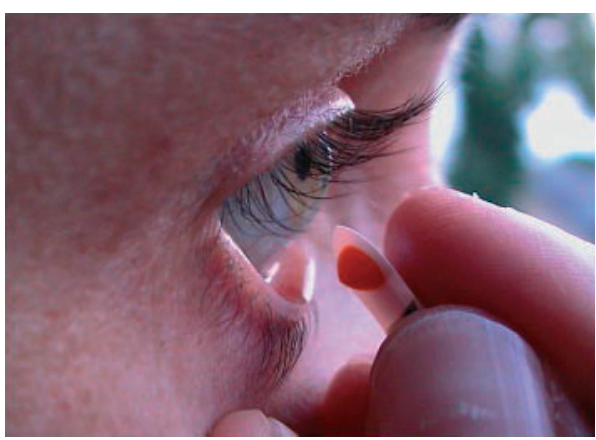

Figure 1 Application of a lyophilisate. 


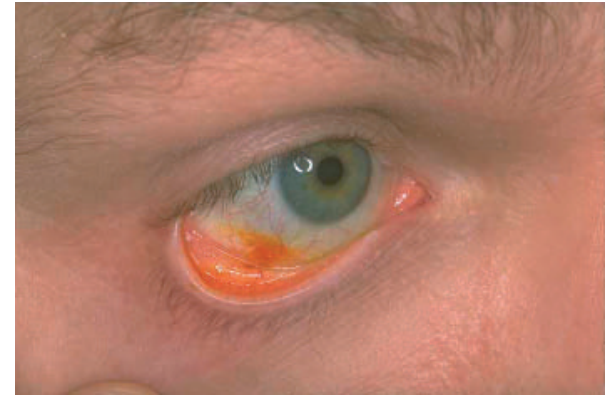

Figure 2 Fluorescein at the cornea.

fluorescein concentrations $(\mathrm{ng} / \mathrm{ml})$ in the cornea and anterior chamber were regarded as equivalent of the bioavailability of each drug delivery device.

At baseline we measured the autofluorescence of the cornea, anterior chamber, and lens before the application of fluorescein. The increase of fluorescence over time $(\mathrm{ng} / \mathrm{ml})$ of the cornea and anterior chamber was measured every 2 minutes for 30 minutes after application. ${ }^{15}$ The fluorescein concentrations of the cornea (C) and anterior chamber (AC) represented the bioavailability from each application system. The statistical significance of the data was evaluated by paired $t$ test (SPSS 10.0 for Windows, Statistical package for the social studies, Chicago, IL, USA).

\section{Part B}

An additional 10 healthy volunteers (six men, four women, mean age: 25 years) applied a lyophilisate to one eye and a preservative free fluorescein eye drop to the fellow eye in a randomised experiment. The fluorescein dose of the lyophilisate was $68 \mu \mathrm{g}$ corresponding to a single, preservative free eye drop of $40 \mu \mathrm{l}$ fluorescein SE $0.17 \%$ (Alcon GmbH, Germany).

Fluorophotometry was performed before, +2 minutes and $+480 ;+600 ;+720$ minutes after application. The fluorescein concentration of cornea (C) and anterior chamber (AC) were analysed by paired $t$ test (SPSS 10.0 for Windows, Statistical package for the social studies, Chicago, IL, USA).

Volunteers wearing contact lenses, who had an injury or infection in either eye within the past 3 months before entering the study, had any kind of ocular surgery, smokers, and those suffering from diabetes were excluded.
The fluorescein dose of the lyophilisate was $68 \mu \mathrm{g}$ corresponding to a single, preservative free eye drop of $40 \mu \mathrm{l}$ fluorescein SE $0.17 \%$ (Alcon GmbH, Germany). The fluorescein lyophilisate is deposited in the lower cul de sac by stripping it off the carrier in a wiping motion over the rim of the lower eyelid (Fig 1). Upon contact with the conjunctiva the lyophilisate immediately rehydrates in the tear film, detaches from the carrier (Fig 2) and is diluted by the tear film. The fluorescein is spread over the cornea and conjunctiva. In contrast with conventional eye drops no additional volume and no preservatives are applied to the surface of the eye. Thus no tearing and washout effect are stimulated.

The tolerability of the two drug delivery forms was assessed by means of $100 \mathrm{~mm}$ arbitrary visual analogue scales (VAS) in which $0 \mathrm{~mm}$ denoted no ocular discomfort and $100 \mathrm{~mm}$ represented severe ocular discomfort. The volunteers documented their ocular tolerability at +1 minute after application.

\section{RESULTS}

Part A

Ten healthy white volunteers completed part A of the study. All measurements could be carried out. The fluorescein profiles of both groups at baseline (see Table 1) before the application of eye drops or lyophilisates showed no significant difference in the cornea and anterior chamber autofluorescence.

\section{Cornea concentrations (C)}

The cornea mean values were significantly higher in eyes treated with the lyophilisate during 30 minutes after application except for two measurements at $+22,+30$ minutes. At +2 minutes the mean fluorescein concentration in the cornea in the lyophilisate group was $3391 \mathrm{ng} / \mathrm{ml}$ compared with $839 \mathrm{ng} / \mathrm{ml}$ of eyes treated with the conventional eye drops (Table 1 and Fig 3). After 30 minutes the mean fluorescein concentration in the cornea of the lyophilisate group decreased to $160.50 \mathrm{ng} / \mathrm{ml}$ compared with $32.98 \mathrm{ng} / \mathrm{ml}$ in the eye drop group. The mean fluorescein concentrations after lyophilisate application were maximum 16.2 times (+10 minutes) and minimum up to four times higher compared with the mean fluorescein concentrations from conventional eye drops.

Table 1 Part A: Fluorescein concentrations $(\mathrm{ng} / \mathrm{ml})$ in the cornea and anterior chamber

\begin{tabular}{|c|c|c|c|c|c|c|c|c|c|c|}
\hline \multirow[b]{3}{*}{ Time (minutes) } & \multicolumn{5}{|l|}{ Cornea } & \multicolumn{5}{|c|}{ Anterior chamber } \\
\hline & \multicolumn{2}{|c|}{ Lyophilisate } & \multicolumn{2}{|c|}{ Eye drops } & \multirow[t]{2}{*}{ p Value } & \multicolumn{2}{|c|}{ Lyophilisate } & \multicolumn{2}{|c|}{ Eye drops } & \multirow[t]{2}{*}{ p Value } \\
\hline & Mean & SD & Mean & SD & & Mean & SD & Mean & SD & \\
\hline 0 & 12.55 & 3.53 & 11.33 & 2.63 & $<0.483$ & 6.25 & 2.84 & 5.35 & 1.96 & $<0.554$ \\
\hline 2 & 3390.99 & 2251.64 & 839.13 & 600.23 & $<0.009$ & 73.75 & 43.63 & 22.67 & 12.33 & $<0.007$ \\
\hline 4 & 3058.79 & 1759.88 & 400.44 & 303.05 & $<0.001$ & 61.18 & 29.90 & 14.59 & 9.53 & $<0.000$ \\
\hline 6 & 2874.19 & 2030.96 & 246.88 & 267.44 & $<0.002$ & 69.96 & 58.94 & 10.25 & 5.51 & $<0.008$ \\
\hline 8 & 2007.50 & 1352.46 & 158.97 & 232.19 & $<0.001$ & 48.97 & 36.39 & 9.67 & 5.83 & $<0.005$ \\
\hline 10 & 2033.17 & 2339.72 & 125.45 & 208.37 & $<0.023$ & 44.92 & 39.94 & 8.84 & 6.46 & $<0.013$ \\
\hline 12 & 1768.04 & 2034.01 & 107.24 & 213.27 & $<0.033$ & 46.35 & 49.76 & 8.01 & 4.84 & $<0.056$ \\
\hline 14 & 1312.99 & 1526.67 & 81.75 & 163.39 & $<0.023$ & 37.82 & 44.66 & 6.93 & 2.97 & $<0.048$ \\
\hline 16 & 850.64 & 1020.11 & 74.49 & 154.55 & $<0.027$ & 22.93 & 21.28 & 6.98 & 2.86 & $<0.041$ \\
\hline 18 & 1076.96 & 1350.76 & 61.72 & 123.14 & $<0.034$ & 31.34 & 33.36 & 6.85 & 3.20 & $<0.041$ \\
\hline 20 & 701.75 & 898.02 & 46.95 & 77.99 & $<0.039$ & 21.71 & 21.95 & 6.67 & 2.62 & $<0.056$ \\
\hline 22 & 669.74 & 902.55 & 51.10 & 83.78 & $<0.054$ & 20.67 & 19.87 & 7.09 & 3.14 & $<0.070$ \\
\hline 24 & 554.47 & 706.71 & 39.91 & 66.99 & $<0.041$ & 17.85 & 16.18 & 6.50 & 2.66 & $<0.060$ \\
\hline 26 & 339.59 & 407.39 & 44.83 & 77.51 & $<0.033$ & 14.06 & 11.78 & 6.58 & 2.44 & $<0.087$ \\
\hline 28 & 246.19 & 318.75 & 45.43 & 72.32 & $<0.047$ & 11.61 & 8.12 & 7.47 & 3.04 & $<0.190$ \\
\hline 30 & 160.50 & 219.39 & 32.98 & 42.15 & $<0.068$ & 10.33 & 6.88 & 6.39 & 2.40 & $<0.142$ \\
\hline
\end{tabular}


Table 2 Part B: Fluorescein concentrations $(\mathrm{ng} / \mathrm{ml})$ in the cornea and anterior chamber

\begin{tabular}{|c|c|c|c|c|c|c|c|c|c|c|}
\hline \multirow[b]{3}{*}{ Time (minutes) } & \multicolumn{5}{|l|}{ Cornea } & \multicolumn{5}{|c|}{ Anterior chamber } \\
\hline & \multicolumn{2}{|c|}{ Lyophilisate } & \multicolumn{2}{|c|}{ Eye drops } & \multirow[b]{2}{*}{ p Value } & \multicolumn{2}{|c|}{ Lyophilisate } & \multicolumn{2}{|c|}{ Eye drops } & \multirow[b]{2}{*}{ p Value } \\
\hline & Mean & SD & Mean & SD & & Mean & SD & Mean & SD & \\
\hline 0 & 12.58 & 3.89 & 11.62 & 3.32 & $<0.644$ & 6.13 & 2.86 & 5.29 & 1.95 & $<0.574$ \\
\hline 2 & 3813.54 & 2587.0 & 917.81 & 860.57 & $<0.011$ & 98.75 & 70.05 & 23.10 & 17.48 & $<0.012$ \\
\hline 480 & 25.39 & 9.71 & 13.20 & 3.93 & $<0.004$ & 9.24 & 5.58 & 5.93 & 2.13 & $<0.049$ \\
\hline 600 & 21.75 & 8.44 & 12.36 & 3.88 & $<0.015$ & 10.86 & 5.23 & 5.46 & 2.50 & $<0.103$ \\
\hline 720 & 21.59 & 11.14 & 15.38 & 9.02 & $<0.044$ & 8.80 & 3.54 & 6.15 & 2.65 & $<0.178$ \\
\hline
\end{tabular}

Anterior chamber concentrations (AC)

All mean fluorescein concentrations of the mid anterior chamber were higher in the lyophilisate group. The anterior chamber mean values were significantly higher up to 20 minutes (except for +12 minutes) in the lyophilisate group $(\mathrm{p}<0.048)$ (Table $\mathrm{l}$ and Fig 4). The AC mean fluorescein concentration of the lyophilisate treated eye reached $73.75 \mathrm{ng} / \mathrm{ml}$ at +2 minutes, decreased to $37.82 \mathrm{ng} /$ $\mathrm{ml}$ at +14 minutes, and reached $10.33 \mathrm{ng} / \mathrm{ml}$ at +30 minutes. The AC mean fluorescein concentration of the conventional eye drop treated eye reached $22.67 \mathrm{ng} / \mathrm{ml}$ at +2 minutes, decreased to $6.93 \mathrm{ng} / \mathrm{ml}$ at +14 minutes, and reached $6.39 \mathrm{ng} /$ $\mathrm{ml}$ at +30 minutes. After 14 minutes the eyes treated with conventional eye drops reached just baseline fluorescein values $(5.35 \mathrm{ng} / \mathrm{ml}$ at baseline compared to $6.93 \mathrm{ng} / \mathrm{ml}$ at +14 minutes).

\section{Part B}

In part $\mathrm{B}$ the additional 10 healthy volunteers finished the protocol. All measurements were carried out. The fluorescein profile of both groups at baseline (see Table 2) before application of eye drop or lyophilisate showed no significant difference in the cornea and anterior chamber autofluorescence profile.

\section{Cornea concentrations}

The mean fluorescein concentrations of the cornea 812 hours after application were significantly higher $(p<0.044)$ in the lyophilisate group. The mean fluorescein concentration in the cornea of the lyophilisate treated eye reached $3813.54 \mathrm{ng} / \mathrm{ml}$ at +2 minutes and decreased to $21.59 \mathrm{ng} / \mathrm{ml}$ at +720 minutes (Table 2 and Fig 5 ). The mean fluorescein concentration in the cornea of the conventional eye drop treated eye reached $917.81 \mathrm{ng} / \mathrm{ml}$ at +2 minutes and decreased to $15.38 \mathrm{ng} / \mathrm{ml}$ at +720 minutes. After 8 hours the eyes treated with conventional eye drops reached just baseline fluorescein values $(11.62 \mathrm{ng} / \mathrm{ml}$ at baseline compared to $13.20 \mathrm{ng} / \mathrm{ml}$ at +480 minutes), whereas the fluorescein concentration in the lyophilisate group at that time point was twice as high $(12.58 \mathrm{ng} / \mathrm{ml}$ at baseline compared to $25.39 \mathrm{ng} / \mathrm{ml}$ at +480 minutes $)$.

\section{Anterior chamber concentrations}

In the anterior chamber the mean fluorescein concentration in the lyophilisate group was significantly higher $(p<0.049)$ up to +8 hours after application (Table 2 and Fig 6). The AC mean fluorescein concentration of the lyophilisate treated eye reached $10.86 \mathrm{ng} / \mathrm{ml}$ at +8 hours compared with $6.13 \mathrm{ng} / \mathrm{ml}$ at baseline. The anterior chamber mean fluorescein concentration of the conventional eye drop treated eye reached $5.93 \mathrm{ng} / \mathrm{ml}$ at +8 hours compared with $5.29 \mathrm{ng} / \mathrm{ml}$ at baseline. After 8 hours no fluorescein is left in eyes treated with conventional eye drops. At +10 and +12 hours the mean fluorescein concentrations did not show any significant difference between both groups.

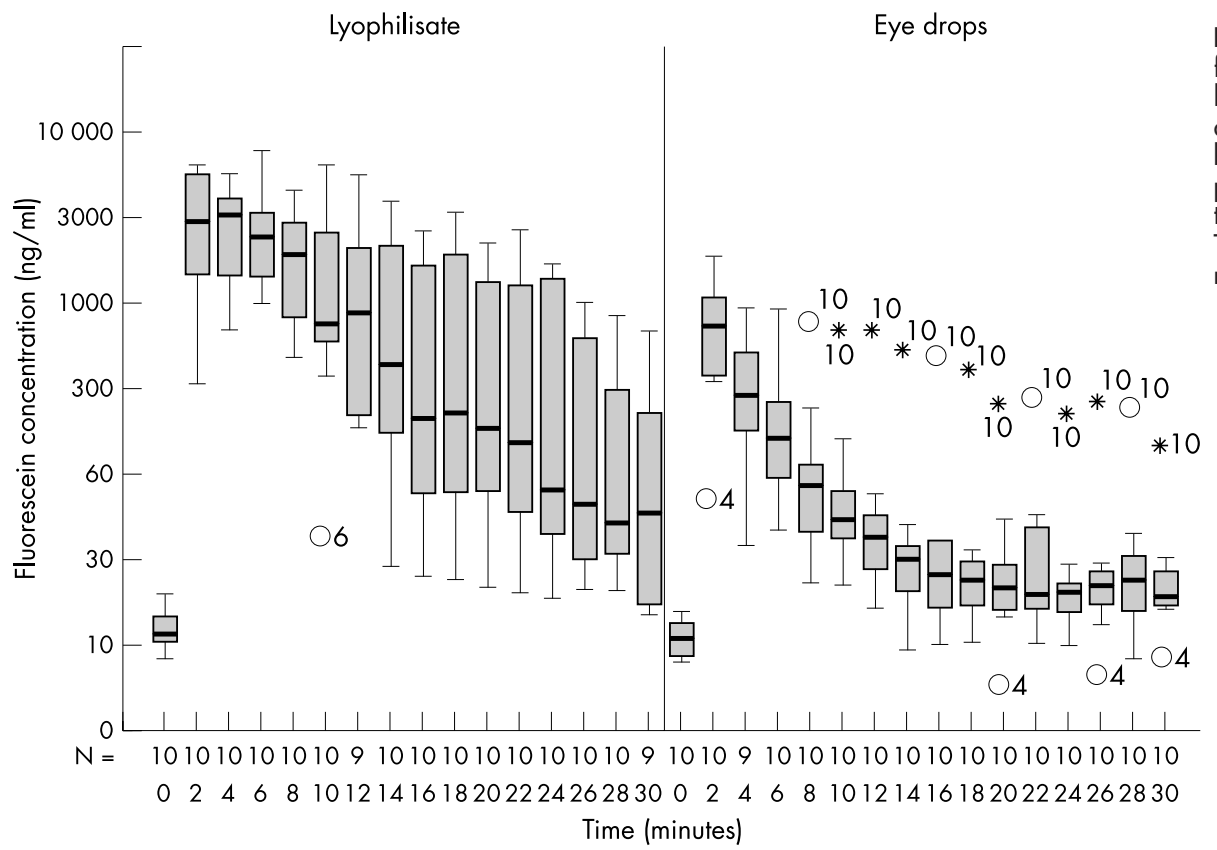




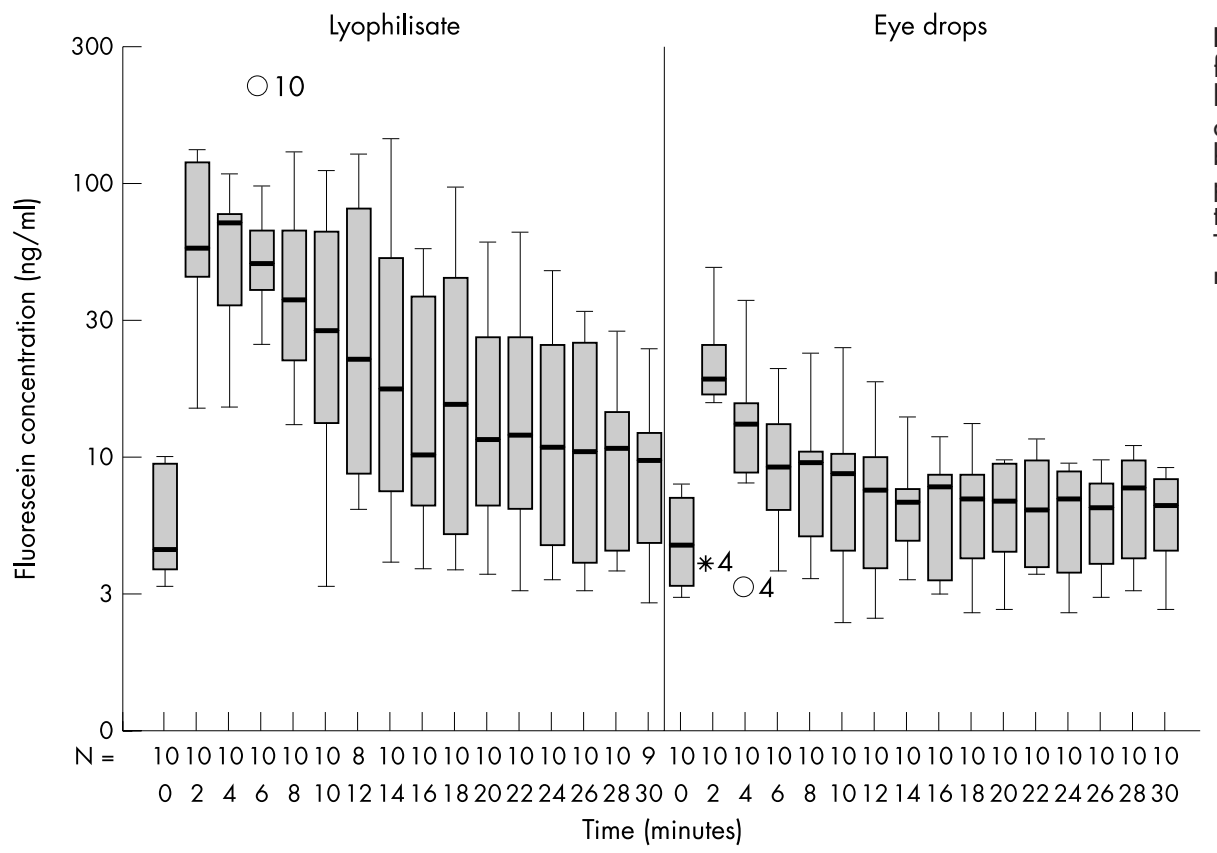

Figure 4 fluorescein concentration flow over time in the anterior chamber: lyophilisate $v$ eye drop; Box plot diagrams: the horizontal lines in the box denote the 25th, 50th, and 75th percentile values. The error bars denote the 5th and the 95th percentile values. The square symbol in the box shows the mean of the data column.

Tolerability

Both forms of application were generally well tolerated. None of the volunteers complained about the application of lyophilisate. The mean ocular discomfort from the preservative free eye drops was statistically seen as significantly lower compared to the lyophilisates $(\mathrm{p}<0.002)$.

\section{DISCUSSION}

This paper marks the fourth clinical test of lyophilisates as a new preservative free single dose ophthalmic drug delivery system (Fig 1).

In phase I in 1999 the safety and tolerability of the lyophilisate was studied successfully by Diestelhorst et al. ${ }^{12}$ In comparison with a conventional, preservative free tear film substitute it demonstrated a very good tolerability and excellent safety. The study showed that the application is very easy. The patient does not need to recline his head, he/ she only has to wipe the tip of the carrier (Fig 1) over the lower lid margin. Compared with the tip of an eye bottle there is no risk of trauma or injury. ${ }^{12}$ In this study the mean ocular discomfort of lyophilisate, measured by VAS, was quite similar to that study $(31.0 \mathrm{~mm}$ compared with $36.3 \mathrm{~mm}$ ). In contrast with lyophilisate is the valuation of eye drops. In 1999 the mean ocular discomfort was $33.0 \mathrm{~mm}$ compared to $11.2 \mathrm{~mm}$ in our study. This difference could perhaps be explained by the small numbers of volunteers in the study (20 volunteers in our study compared to 32 volunteers in the study of Diestelhorst). ${ }^{12}$

In 2000 Dinslage et al ${ }^{1}$ compared the ocular bioavailability of a single dose of fluorescein $(68 \mu \mathrm{g})$ from lyophilisate with

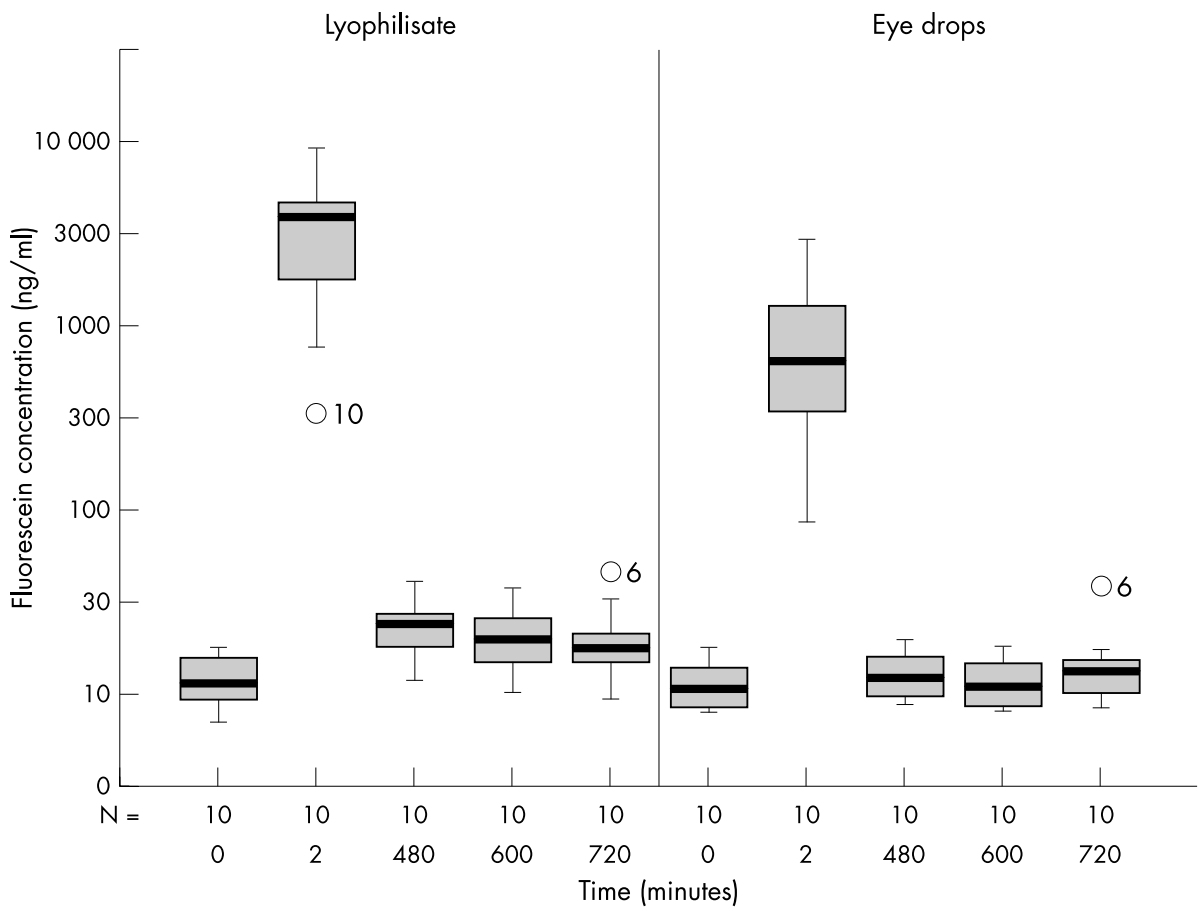

Figure 5 Fluorescein concentration flow over time in the cornea: lyophilisate $v$ eye drop; Box plot diagrams: the horizontal lines in the box denote the 25th, 50th, and 75th percentile values. The error bars denote the 5th and the 95th percentile values. The square symbol in the box shows the mean of the data column. 


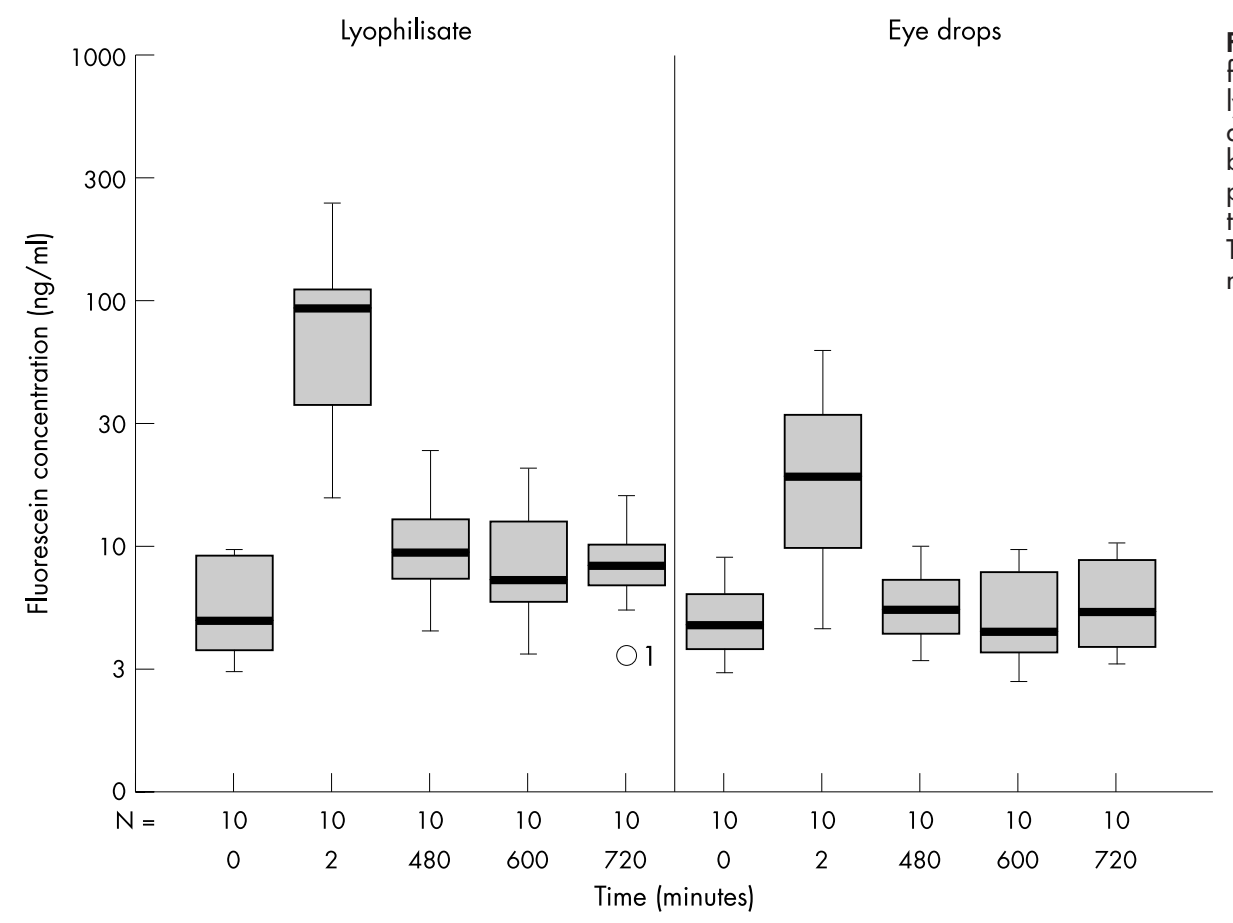

Figure 6 Fluorescein concentration flow over time in the anterior chamber: lyophilisate $v$ eye drop. Box plot diagrams: the horizontal lines in the box denote the 25th, 50th, and 75th percentile values. The error bars denote the 5th and the 95th percentile values. The square symbol in the box shows the mean of the data column.

that of conventional eye drops during the first 3 hours after application. The authors found significantly higher mean values of lyophilisate in the cornea and anterior chamber in comparison with a single conventional eye drop. Even 3 hours after lyophilisate instillation they still reported increasing mean fluorescein concentrations in the anterior chamber.

Lux et al compared the ocular bioavailability of fluorescein from a triple dose $(204 \mu \mathrm{g})$, single lyophilisate with three conventional eye drops. Their data have shown significantly higher bioavailability of fluorescein in both the cornea and the mid anterior chamber up to 7 hours in the eyes treated with lyophilisate. ${ }^{16}$

Our intention was to examine the first 30 minutes after application in part A and the long term bioavailability up to 12 hours after application of lyophilisate compared with conventional eye drops in part B. During the first 30 minutes after application, the corneal stroma (C) mean fluorescein concentrations in eyes treated with lyophilisates were $4 \times$ higher after 2 minutes, $16 \times$ higher after 14 minutes, and $5 \times$ higher after 30 minutes (Table 1). Therefore, with lyophilisate a substantially higher drug concentration in the cornea is accessible.

The mid anterior chamber mean fluorescein concentrations in the eyes treated with eye drops reached baseline fluorescein values after 14 minutes, whereas at that time the fluorescein concentration in the lyophilisate group was six times higher then baseline. Our results in part B underline that the long term drug effect from the lyophilisate is significantly better. In the anterior chamber the mean fluorescein concentrations were significantly higher up to 8 hours $(p<0.049)$ and in the cornea even up to 12 hours $(\mathrm{p}<0.044)$ after application in the lyophilisate group. These results demonstrate that topical instillation of conventional ophthalmic solutions relies on "pulse entry" of the drug which is characterised by a rapid rise followed by a rapid decline in the ocular drug concentration. Lyophilisate, on the other hand, shows a rapid rise but not a rapid decline in the ocular bioavailability.

Our data are in agreement with the study of Dinslage et al. ${ }^{1}$ The authors found cornea and anterior chamber concentrations barely exceeding autofluorescence values +15 minutes after application of $40 \mu \mathrm{l}$ of a fluorescein $0.17 \%$ eye drop. The anterior chamber concentrations did not increase statistically in a significant way at all time points up to 3 hours after application.

The poor long term drug effects of conventional eye drops measured in our study occur for several reasons. The main reason is the rapid elimination of conventional eye drops from the eye. This results in extensive drug loss. Only a small amount $(1-3 \%)$ actually penetrates the cornea and reaches intraocular tissues. ${ }^{17-19}$ The reasons for this inefficient drug delivery lie in a rapid tear turnover, lacrimal drainage, and drug dilution tears. ${ }^{20}$ The consequence is that high concentrations have to be used in conventional ocular therapy.

Ocular medications rapidly drain via the nasolacrimal duct to the nasal mucosa causing systemic side effects. A possible alternative is the lyophilisate: a water free, true single dose, $\mathrm{pH}$ neutral, and preservative free drug delivery device which avoids the rapid dilution of medications at the tear film. A significantly better intraocular bioavailability was demonstrated by different investigators. Another advantage of lyophilisate is the absence of preservatives. Preservatives are known to cause cytotoxic reactions to the ocular surface: blepharitis, conjunctivitis, conjunctival hyperaemia, and punctate keratitis. ${ }^{21-24}$ In particular patients with chronic ocular surface disease (glaucoma, dry eye syndrome or allergies) are more sensitive to preservatives and should consequently use preservative free eye medication. ${ }^{72526}$ Pisella et al investigated the prevalence of ocular symptoms and signs with preserved and preservative free glaucoma medication. The authors concluded that the use of preservative free eye medication clearly reduces the signs of ocular surface irritation in glaucoma patients. ${ }^{27}$

Lyophilisates containing antiglaucoma medications are able to maintain a relatively high and steady concentration of the medication in the cornea and anterior chamber over a longer period of time. The application could be set at longer intervals resulting in more comfort for the patient as well as better compliance. In the treatment of corneal infections this delivery device may also be a possible alternative since much higher concentrations of antibiotics or antimycotics in the 
cornea could be reached. The depot effect of the lyophilisate should be used in the treatment of the dry eye syndrome. If the superior bioavailability of medications applied with a lyophilisate can be demonstrated in, for example, glaucoma patients this device may replace today's pharmaceutical ocular therapy.

\section{ACKNOWLEDGEMENTS}

We would like to thank Dr Silke Coburger, University of Cologne for her help in statistics.

\section{Authors' affiliations}

A Steinfeld, A Lux, M Diestelhorst, Department of Ophthalmology, University of Cologne, Germany

S Maier, R Süverkrüp, Department of Pharmaceutical Technology, University of Bonn, Germany

R Süverkrüp and M Diestelhorst have a proprietary interest in the device.

Correspondence to: A Steinfeld, Department of Ophthalmology, University of Cologne, Germany; persteinfeld@yahoo.com

Accepted for publication 17 March 2003

\section{REFERENCES}

1 Dinslage S, Diestelhorst M, Weichselbaum A, et al. Lyophilisates for drug delivery in ophthalmology: pharmacokinetics of fluorescein in the human anterior segment. $\mathrm{Br} J$ Ophthalmol 2002;86:10-13.

2 Le Bourlais C, Acar L, Zia H, et al. Ophthalmic drug delivery systems-recent advances. Prog Ret Eye Res 1998:17:33-58.

3 Brown MM, Brown GC, Spaeth GL. Improper topical self-administration of ocular medication among patients with glaucoma. Can J Ophthalmol 1984;19:1-6

4 DeSantis LM, Patil PN Pharmacokinetics. In: Havener WH, ed. Ocular pharmacology, 6th ed. St Lovis: Mosby, 1994:22-45.

5 Fraunfelder FT. Drugs used primarly in ophthamolgy. In: Drug-induced ocular side effects, 4th ed. Baltimore: William \& Wilkins, 1996:420-43.

6 Sugrue MF. The pharmacology of antiglaucomatous drugs. Pharm Ther 1989:43:91-138.

7 Furrer P, Mayer J, Gurny R. Ocular tolerance of preservatives and alternatives. Eur J Pharm Biopharm 2002;53:263-80.
8 Olson $\mathbf{R}$, White $\mathrm{G}$. Preservatives in ophthalmic topical medications: a significant cause of disease. Cornea 1990;9:363-4.

9 Alani SD. The ophthalmic rod: a new ophthalmic drug delivery system. Graefes Arch Clin Exp Ophthalmol 1990;228:297-301.

10 Diestelhorst $M$, Krieglstein GK. The ocular tolerability of a new ophthalmic drug delivery system (NODS). Int Ophthalmol 1994;18:1-4.

11 Shell JW. Ophthalmic drug delivery systems. Drug Dev Res 1985;6:245-61.

12 Diestelhorst M, Grunthal S, Süverkrüp R. Dry drops: a new preservative-free drug delivery system. Graefes Arch Clin Exp Ophthalmol 1999;237:394-8.

13 McLaren JW, Brubaker RF. A two-dimensional scanning ocular fluorophotometer. Invest Ophthalmol Vis Sci 1985;26:144.

14 Munnerlyn CR, Gray JR, Hennings DR. Design considerations for a fluorophotometer for ocular research. Graefes Arch Clin Exp Ophthalmol 1985;222:209

15 Mosier MA, Gray JR, Ishimoto BM. Ocular fluorophotometer analysis. Curr Eye Res 1983;2:699.

16 Lux A, Diestelhorst M, Sueverkruep R. Comparative bioavailability study of identical doses of fluorescein: three eye drops $v$ a single lyophilisate: $\mathrm{Br} J$ Ophthalmol, (in press).

17 Patton TF, Franceur M. Ocular bioavailability and systemic loss of topically applied ophthalmic drugs. Am J Ophthalmol 1978;85:225-9.

18 Patton TF, Robinson JR. Quantitative precorneal disposition of topically applied pilocarpine nitrate in rabbit eyes. J Pharm Sci 1976:65:1295-301.

19 Wood R, Li V, Robinson JR. Ocular disposition of poly-hexyl-2.cyano[3-14] acrylate nanoparticles in the albino rabbit. Int J Pharm 1985;23:175-83.

20 Lee VHL, Robinson JR. Mechanistic and quantitative evaluation of precornal pilocarpine disposition in albino rabbits. J Pharm Sci 1979:68:673-84.

21 Van Beek LM, de Keizer RJ, Polak BC, et al. Incidence of ocular side effects of topical $\beta$ blockers in the Netherlands. $\mathrm{Br} J$ Ophthalmol 2000;84:856-9.

22 Burstein NL. Corneal cytotoxicity of topically applied drugs, vehicles and preservatives. Surv Ophthalmol 1980:25:15-30.

23 Gasset AR, Ishii Y, Kaufmann HE, et al. Cytotoxity of ophthalmic preservatives. Am J Ophthalmol 1974;78:98-105.

24 Becquet F, Goldschild M, Moldovan MS, et al. Histopathological effects of topical ophthalmic preservatives on rat corneoconjuntival surface. Curr Eye Res 1998;17:419-25.

25 Lemp MA, Zimmermann LE. Toxic endothelial degeneration in ocular surface disease treated with topical medications containing benzalkonium chloride. Am J Ophthalmol 1988; 105:670-3.

26 Marquart R, Schubert T. Beeinflussung der Traenenfilmaufreisszeit (BUT) durch Betablocker-Augentropfen ohne Konservierungstropfen. Klin Monatsbl Augenheilkd 1991;199:75-8.

27 Pisella PJ, Pouliquen P, Baudouin C. Prevalence of ocular symptoms and signs with preserved and preservative free glaucoma medication. $\mathrm{Br} J$ Ophthalmol 2002;86:418-23. 